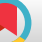

\title{
Association of the Meta-Emotion Structure with the Dimensions of Emerging Adulthood Identity Mediated by Mental Health in University Students
}

\author{
Camelia Sadati (iD ${ }^{1}$, Hooman Namvar (iD ${ }^{2,}{ }^{*}$ and Bita Nasrolahi (iD ${ }^{1}$ \\ ${ }^{1}$ Department of Psychology, Science and Research Branch, Islamic Azad University, Tehran, Iran \\ ${ }^{2}$ Department of Psychology, Saveh Branch, Islamic Azad University, Saveh, Iran \\ "Corresponding author: Department of Psychology, Saveh Branch, Islamic Azad University, Saveh, Iran. Email: homnnamvar@gmail.com
}

Received 2021 October 01; Revised 2021 November 06; Accepted 2021 November 20.

\begin{abstract}
Background: Meta-emotion is a crucial developmental task to maintain internal balance, provide compatible relations, and improve mental health.

Objectives: The present study aimed to investigate the association of the meta-emotion structure with the dimensions of emerging adulthood identity mediated by mental health in university students.

Methods: This descriptive-correlational study was conducted on male and female university students aged 18 - 25 years who were selected from the public universities of Tehran, Iran during 2020 - 2021. The research sample consisted of 178 participants selected via convenience, quota, and nonrandom sampling. Data were collected using Arnett's inventory of the dimensions of emerging adulthood (IDEA), Goldberg's general health questionnaire-12 (GHQ-12), and Mitmansgruber's Meta-Emotion scale (MES). Data analysis was performed using structural equation modeling in the SmartPLS-3 software.

Results: The meta-emotion structure had a significant negative association with possibilities/optimism $(r=-0.14)$ and significant positive associations with the components of feeling in-between, identity explorations, self-focus, and possibilities/optimism. Mental health had a negative association with possibilities/optimism $(r=-0.17)$ and positive associations with the other four identity dimensions. In terms of the direct influence coefficients, the meta-emotion structure had a direct and significant influence only on mental health $(r=0.68)$. Furthermore, mental health had a direct effect only on instability/negativity. Among the identity dimensions of emerging adulthood, mental health had a mediating role only for instability/negativity $(\beta=0.21 ; \mathrm{t}=3.23)$.

Conclusions: According to the results and considering the structure of meta-emotion and mental health as an influential factor in characteristics such as instability/negativity among identity dimensions, emphasizing mental health as a mediating factor for the association between meta-emotion and components such as instability/negativity could help acquire a better understanding of the association between these variables.
\end{abstract}

Keywords: Meta-Emotion, Mental Health, Identity, Optimism, Instability

\section{Background}

Admission to university and living in a dormitory is a great portion of the lived experience of most humans in the modern society. More than four million students are studying in disparate universities in Iran, constituting a crucial and considerable part of the activists in the scientific community (1). Psychological problems increase during adolescence and youth, even while living in normal conditions. Approximately $15 \%-20 \%$ of adolescents and youngsters experience a period of depression (2). According to a study by Gomes et al. (3), approximately $20 \%$ of youths suffer from at least one type of psychological disorder while transitioning into adulthood. Therefore, it is essential to regard youngsters aged 15 - 24 years as a vulnerable population and a specific targets for interventions. Mental health is a principal factor in adolescents' quality of life. Individuals with psychological disorders and issues are faced with functional inability and failure and lose the opportunity to develop self-esteem and efficient identity, which are crucial in becoming successful adults in the future (4).

The feeling of identity development appears in adolescents to help withstand social desires, the challenges of the developmental period, and the endeavors to give meaning to choices and commitments in life (5). Adolescents' mental health is influenced by identity exploration, the type 
of identity base, and the styles of information processing. Therefore, consistency in identity dimensions and creating an integrated whole during emerging adulthood could result in the highest level of mental health $(6,7)$. In this regard, Jung et al. (8) concluded that personality disorders and mental health issues such as internalized disorders influence and may disrupt adolescents' identity exploration. Psychological issues also affect self-esteem and the identity exploration of individuals.

Arnett (9) proposed the theory of emerging adulthood as cultural-developmental psychology, which encompasses the age range of 18 - 25 years (i.e., the end of adolescence up to the beginning of adulthood). The theory of emerging adulthood is defined as identity characteristics as an in-between growth stage. In this theory, the first characteristic is identity exploration, which occurs during the late adolescents, the early youth, and the midtwenties. In this period, adolescents are seeking the answer to the fundamental question "Who am I?" and start exploring their personal background, environment, and facilities, especially in terms of their options in love and the associated concerns. Another characteristic is possibilities/optimism, through which an individual faces endless possibilities with respect to their potential abilities, optimism toward the future, and life expectancy, seeking to acquire information and make important life decisions. The third characteristic is instability/negativity, which encompasses the exploration of identity, seeking a social role, and values of life in association with disparate and unstable choices, decisions, and planning for education, occupation, and love. The next characteristic is self-focus; compared to socialization during adolescence, this period signifies the beginning of individualism. Therefore, individuals focus their thoughts on themselves in order to achieve stability regarding their roles and choices about education, occupation, and love life and make great decisions concerning their life goals in order to be recognized as independent and self-sufficient individuals. Finally, the theory proposed the characteristic of feeling in-between, which is associated with exploring identity, as well as the instability and negativity of transition to adulthood to distinguish adolescence from adulthood (10).

Based on the meta-emotional or metacognitive model of emotional processing, the manner of conceptualizing emotions and strategies for responding to emotions has a tremendous impact on the persistence of mental health problems (11). Meta-emotion is defined as organizing the collection of thoughts and feelings about one's emotions. In other words, meta-emotion is the emotional reactions of individuals to the emotions that they experience (12). The ability to regulate emotions (i.e., meta-emotion) is a crucial developmental task to maintain individuals' internal balance, provide compatible relations, and improve mental health. Numerous methods have been proposed for the conceptualization of emotion regulation. Some conceptualizations have emphasized emotion regulation, control of emotional experiences or its pretension (especially in controlling negative emotions), and the reduction of emotional arousal (13). Contrarily, others have emphasized the functional nature of emotions in regulating emotions, denoting that emotion regulation does not signify emotion control. Therefore, negative emotions may not subside immediately. Meta-emotion is also a significant determinant of wellbeing and successful performance and may restore or disrupt the capacity of an individual for working, communicating with others, and enjoying possibilities (14).

Meta-emotion skills could help an individual alternate between strategies of emotion regulation with a deductive system, bonding system, transition system, and schematic model system (15). The schematic model system is a high-level system within which dynamic models are constructed, constantly changing themselves and the world and leading to total executive control. This is the most transparent system to manifest meta-emotion skills (16). Emotions indicate whether the individual has achieved their values and desirable states/behaviors in line with their selected goals. In other words, it reveals an individual's self-value and unified identity (17).

\section{Objectives}

A literature review demonstrated a lack of research regarding the association between meta-emotion factors and identity with the mediating role of mental health as a structural model. Therefore, the present study aimed to investigate the association of the meta-emotion structure with the dimensions of emerging adulthood identity mediated by mental health in university students.

\section{Methods}

This descriptive-correlational study was conducted on male and female university students aged 18 - 25 years who were selected from the public universities of Tehran, Iran during 2020 - 2021. The research sample consisted of 178 participants (49 males and 129 females) who were selected via convenience, quota, and nonrandom sampling. Initially, one university was selected from each geographical direction of Tehran, and four public universities were selected for sampling.

Data were collected using four questionnaires in the form of an integrated electronic questionnaire due to the COVID-19 pandemic and the closing of the universities. 
The questionnaires were virtually uploaded to the official channel of the target public universities. The students were asked to select an option based on the instructions mentioned in each paragraph of the questionnaire and submit the questionnaire after completion. In total, 180 electronic questionnaires were collected, and two incomplete questionnaires were eliminated. Finally, 178 questionnaires were statistically analyzed.

For ethical considerations, written informed consent was obtained from the participants, and the study protocol was approved by the Ethics Committee of the Islamic Azad University, Science and Research Branch in Tehran.

\subsection{Research Instruments}

\subsubsection{Arnett's Inventory of the Dimensions of Emerging Adult- hood}

The inventory of the dimensions of emerging adulthood (IDEA) has been designed by Reifman et al. (18) with 31 articles and six subscales, including identity exploration, possibilities/optimism, instability/negativity, selffocus, feeling in-between, and other-focus. The items in the IDEA are scored based a four-point Likert scale (strongly disagree $=1$, partially disagree $=2$, partially agree $=3$, and strongly agree $=4$ ). Based on the instructions, the respondents should imagine their life within five recent years (two years before, the current year, and two upcoming years) and answer the questions based on their personal characteristics and level of agreement. The items are accumulated in a subscale on average for each participant, and the mean scores of the groups are calculated. The higher scores of the subscales signify the higher level of the respective structure. The total score of the IDEA is obtained from the accumulation of the subscale scores, except for the subscale of other-focus. Notably, the subscale of 'otherfocus' is not part of the main conceptual framework of the EA, and its score is not added to the total score of the other five subscales. Fathi et al. (19) have reported the Cronbach's alpha coefficient of 0.83 for the IDEA, and the Cronbach's alpha coefficient was estimated at 0.80 in the present study.

\subsubsection{Goldberg's General Health Questionnaire-12}

Goldberg's general health questionnaire-12 (GHQ-12) was developed by Goldberg in 1972 with 12 items and four dimensions of physical symptoms, anxiety/insomnia, social dysfunction, and chronic depression. The items are scored based on a four-point Likert scale, and the optimal cutoff point of the GHQ-12 has been estimated at nine. To determine this cutoff point and considering the maximum sensitivity, the determined score was five, and the maximum specificity score was calculated to be 15 for a singlestep study. Montazeri et al. (20) have also reported the
Cronbach's alpha coefficient of 0.87 for the GHQ-12, and the Cronbach's alpha coefficient was estimated at 0.83 in the present study.

\subsubsection{Mitmansgruber's Meta-Emotion Scale}

Mitmansgruber's Meta-Emotion scale (MES) was developed by Mitmansgruber in 2009 with 28 items and eight subscales, including anger, compassionate care, interest, contempt/shame, thought control, and suppression. MES is based on two indices of the general viewpoint of an individual regarding positive and negative emotional experiences, and the total score of these indices shows the general viewpoint of the individual concerning different emotional experiences. Parsaei et al. (21) have reported the Cronbach's alpha coefficient of 0.75 for the scale, and the Cronbach's alpha coefficient was estimated at 0.81 in the present study.

\subsection{Statistical Analysis}

Data analysis was performed using descriptive statistics (e.g., mean, standard deviation, and Pearson's correlation-coefficient) and inferential statistics (structural equation modeling and correlation) in the SmartPLS-3 software.

\section{Results}

In terms of demographic variables, $72.5 \%$ of the students $(n=129)$ were female, $27.5 \%(n=49)$ were male, $25.8 \%$ $(n=46)$ were aged 18 -20 years, $44.9 \%(n=80)$ were aged 20 22 years, and $29.2 \%(n=52)$ were aged $22-24$ years. In terms of education level, $84.8 \%$ of the students $(n=151)$ were undergraduates, $11.8 \%(n=21)$ were postgraduates, and $3.4 \%$ $(n=6)$ were PhD candidates. Table 1 shows the descriptive statistics of the study variables, including mean, standard deviation (SD), skewness, and kurtosis.

In the present study, the meta-emotion viewpoint was considered the independent variable of the model, and the six components were regarded as its indices. Mental health was the mediating variable, and the 12 items of the inventory were its indices. In addition, the five components of emerging adulthood were considered the latent dependent variables. Notably, the component of otherfocus was not included in the model since it was not part of the emerging adulthood framework. Initially, the factor loads of the indices were examined, and the indices with a factor load of less than 0.4 were eliminated. In the component of interest, four items pertaining to mental health and 13 items pertaining to emerging adulthood were eliminated as well. After these modifications, the factor loads of all the indices were above 0.4 . Figure 1 shows the modified model. 


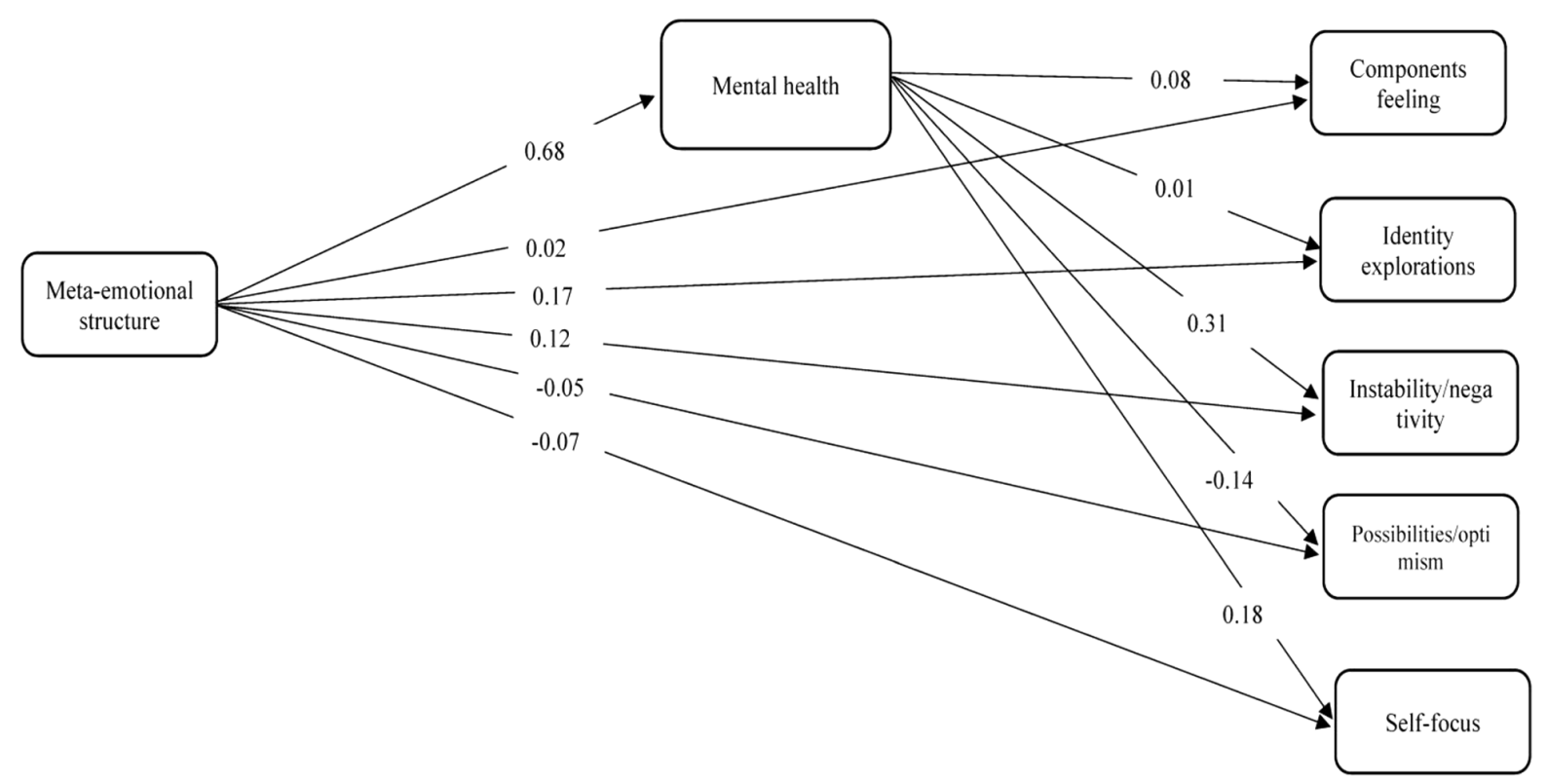

Figure 1. modified model about the mediating role of mental health in the relationship between meta-emotion structure and the dimensions of emerging adulthood identity

Table 1. Mean, Standard Deviation (SD), Skewness, and Kurtosis Among the Study Variables $(\mathrm{n}=178)$

\begin{tabular}{lccc}
\hline Variables & Mean \pm SD & Skewness & Kurtosis \\
\hline Mental health & $14.59 \pm 6.86$ & 0.52 & -0.25 \\
\hline Components feeling & $9.39 \pm 1.54$ & -0.97 & 2.23 \\
\hline Identity explorations & $23.82 \pm 3.12$ & -1.10 & 1.54 \\
\hline Possibilities/optimism & $15.87 \pm 2.11$ & -0.22 & 0.17 \\
\hline Instability/negativity & $19.34 \pm 4.09$ & -0.15 & -0.55 \\
\hline Self-focus & $19.85 \pm 2.37$ & -0.59 & 1.09 \\
\hline Anger & $13.48 \pm 4.42$ & -0.03 & -0.71 \\
\hline Contempt/shame & $18.22 \pm 5.95$ & -0.09 & -0.64 \\
\hline Anger control & $17.82 \pm 5.31$ & 0.10 & -0.46 \\
\hline Suppression & $6.24 \pm 1.65$ & -0.10 & 0.60 \\
\hline Interest & $20.50 \pm 4.51$ & -0.22 & 0.18 \\
\hline Compassionate care & $23.48 \pm 6.22$ & -0.29 & -0.12 \\
\hline
\end{tabular}

Abbreviation: SD, standard deviation.

The reliability of the variables was examined by composite validity, and the minimum and maximum composite validity rates were estimated at 0.75 and 0.90 for self-focus and mental health, respectively. Therefore, the appropriate reliability of the latent variables was confirmed. The minimum extracted mean variance was also calculated to be 0.52 for mental health and instability/negativity. In addition, the maximum value belonged to the dimensions of feeling in-between (0.72), and the extracted mean variance of $>0.5$ confirmed the convergent reliability of the latent variables (Table 2).

\begin{tabular}{lcc}
\hline Table 2. The Reliability of the Variables with Composite Validity \\
\hline Variables & $\begin{array}{c}\text { Composite } \\
\text { Reliability }\end{array}$ & $\begin{array}{c}\text { Average Variance } \\
\text { Extracted }\end{array}$ \\
\hline Components feeling & 0.83 & 0.72 \\
\hline Identity explorations & 0.87 & 0.57 \\
Self-focus & 0.75 & 0.67 \\
Meta-emotional & 0.85 & 0.55 \\
structure & 0.90 & 0.52 \\
Mental health & 0.77 & 0.62 \\
\hline Possibilities/optimism & 0.81 & 0.52 \\
\hline Instability/negativity & & \\
\hline
\end{tabular}

According to the information in Table 3, the correlation results indicated that the meta-emotion structure had a positive association with mental health $(r=0.68)$ and a negative association with possibilities/optimism ( $\mathrm{r}=$. 0.14). Furthermore, positive significant associations were observed with the components feeling in-between, identity exploration, self-focus, and possibilities/optimism. Mental health had a negative association with possibilities/optimism ( $\mathrm{r}=-0.17$ ) and positive associations with the other identity dimensions of emerging adulthood in the students.

Table 4 shows the direct effects of the coefficients. Ac- 


\begin{tabular}{|c|c|c|c|c|c|c|c|}
\hline Variables & 1 & 2 & 3 & 4 & 5 & 6 & 7 \\
\hline 1- Components feeling & 0.85 & & & & & & \\
\hline 2-Identity explorations & 0.28 & 0.75 & & & & & \\
\hline 3-Self-focus & 0.33 & 0.53 & 0.78 & & & & \\
\hline 5-Mental health & 0.10 & 0.11 & 0.14 & 0.68 & 0.72 & & \\
\hline 6- Possibilities/optimism & 0.13 & 0.24 & 0.29 & -0.14 & -0.17 & 0.79 & \\
\hline 7-Instability/negativity & 0.03 & 0.13 & 0.02 & 0.33 & 0.39 & -0.19 & 0.72 \\
\hline
\end{tabular}

cordingly, the value of $\mathrm{t}>1.96$ demonstrated the statistical significance of the coefficient. The meta-emotion structure had a significant direct influence only on mental health, and its effect size manifested a significant influence in this regard $\left(\beta=0.68 ; \mathrm{t}=17.39 ; \mathrm{f}^{2}=0.85\right)$. Moreover, mental health had a direct impact on instability/negativity and a small effect size $\left(\beta=0.3 ; \mathrm{t}=3.42 ; \mathrm{f}^{2}=0.06\right)$.

The mediating role of mental health was investigated concerning the effects of the meta-emotion structure on the dimensions of emerging adulthood with indirect coefficients (Table 5). According to the information in Table 5, the indirect coefficient of the meta-emotion structure significantly affected instability/negativity only $(\beta=0.21$ and $t$ =3.23). Therefore, mental health had a mediating role only for instability/negativity among the other dimensions of emerging adulthood.

\section{Discussion}

The present study aimed to investigate the association of the meta-emotion structure with the dimensions of emerging adulthood identity, mediated by mental health, in university students. The obtained results indicated that the meta-emotion structure had a positive association with mental health and a negative association with possibilities/optimism. Furthermore, positive significant associations were observed with the components feeling in-between, identity exploration, self-focus, and possibilities/optimism. On the other hand, mental health had a negative association with possibilities/optimism and positive associations with the other identity dimensions of emerging adulthood in the university students. Our findings also indicated that the indirect coefficients of metaemotion on instability/negativity were significant. In addition, mental health had a mediating role only for instability/negativity, which is consistent with the findings of Jung et al. (8) and Yanos et al. (22).

In describing the mediating role of mental health in the association between the meta-emotion and instabil- ity/negativity identity style, it could be argued that metaemotion is a meta-cognition and meta-cognitive strategy. In terms of metacognitive emotional disorders, selecting a strategy for emotional regulation is affected by the metacognitive beliefs of an individual regarding the necessity and outcomes of the selected strategy. However, these strategies have a negative impact on the individuals' attention threshold in identifying the information that contradicts false beliefs (23). The metacognitive theory plays a pivotal role in the beliefs regarding psychological states, including beliefs about emotions and maintenance of distress. Individual differences in metacognitive disorders pertain to the perception of the association between perceived stress, cognition, and negative emotions. A basic principle in this approach is that beliefs and metacognitive components direct the thinking and coping activity of the individual. Individuals with high levels of cognitive selfawareness constantly pay attention to their thoughts, control their thoughts, and particularly heed their mental performance. As a result, they claim to have control over their emotions (24).

Meta-emotion is defined as organizing a collection of thoughts and feelings about emotions. Meta-emotion is concerned with the affective and metacognitive responses of an individual regarding their initial emotions. Metaemotion beliefs are an inherent element of emotion regulation strategies and enable individuals to respond to environmental events with more flexibility (25). The mutual interaction of emotion and memory occurs at various stages of information processing, from the initial coding and stabilization of memory traces to long-term retrieval. Metaemotion reflects and supports the emotions of an individual to improve their health since positive meta-emotion lays the groundwork for accenting the emotions of oneself (26). This notion signifies that meta-emotion has a positive nature and may describe the processes of mindfulness and psychological acceptance, thereby resulting in health improvement.

Mindfulness arising from meta-emotion enables an in- 


\begin{tabular}{|c|c|c|c|c|c|c|}
\hline \multirow{2}{*}{ Variables } & \multicolumn{3}{|c|}{ Meta-Emotional Structure } & \multicolumn{3}{|c|}{ Mental Health } \\
\hline & $\beta$ & $\mathbf{t}$ & $\mathbf{f}^{2}$ & $\beta$ & $\mathbf{t}$ & $\mathbf{f}^{2}$ \\
\hline Components feeling & 0.02 & 0.16 & 0.000 & 0.08 & 0.59 & 0.004 \\
\hline Identity explorations & 0.17 & 0.92 & 0.016 & 0.01 & 0.01 & 0.000 \\
\hline Self-focus & -0.07 & 0.5 & 0.003 & 0.18 & 1.52 & 0.019 \\
\hline Mental health & 0.68 & $17.39^{a}$ & 0.851 & - & - & - \\
\hline Possibilities/optimism & -0.05 & 0.41 & 0.001 & -0.14 & -0.14 & 0.011 \\
\hline Instability/negativity & 0.12 & 1.36 & 0.009 & 0.31 & 0.31 & 0.063 \\
\hline
\end{tabular}

${ }^{\mathrm{a}} \mathrm{P}<0.05$.

\begin{tabular}{lcc}
\hline $\begin{array}{l}\text { Table 5. Indirect Path Coefficients of Meta-Emotional Structure with Mediating Role } \\
\text { of Mental Health on Dimensions of Emerging Adulthood }\end{array}$ \\
\hline Variables & $\beta$ & $\mathbf{t}$ \\
\hline Components feeling & 0.060 & 0.58 \\
\hline Identity explorations & 0.001 & 0.01 \\
\hline Self-focus & 0.120 & 1.50 \\
\hline Possibilities/optimism & -0.100 & 1.25 \\
\hline Instability/negativity & 0.210 & $3.23^{\mathrm{a}}$ \\
\hline${ }^{\mathrm{a}} \mathrm{P}<0.05$. & & \\
\hline
\end{tabular}

dividual to perceive a situation or event as it is without activating the negative affective states pertinent to the situation. Consequently, the individual will be able to consider a broad spectrum of targeted responses and produce selective and self-regulated responses instead of responding automatically (27). Presence of mind and attention control are considered effective in this regard, helping patients to be fully aware of their thoughts, affect/accept their thoughts, remain in a peaceful and focused state without judgment, and control their thoughts. Acquiring this ability helps individuals feel more in control in every affair in life and respond to every situation with more control, peace, and awareness rather than responding automatically (28). As a result, emotional stability could be attained, which mitigates negative emotions and brings about identity integration.

The main limitations of the present study were nonrandom sampling and self-report data collection, which might have affected the results. Therefore, it is recommended that other methods (e.g., interviews) be employed in further studies. Moreover, our study was performed on male and female university students aged 18 - 25 years who were selected from the public universities of Tehran. As such, generalizing the findings to other communities should be with caution.

\subsection{Conclusions}

According to the results and considering the metaemotion structure and mental health as an influential factor in characteristics such as instability/negativity (identity dimensions), mental health should be emphasized as a mediating factor in the association between meta-emotion and components such as instability/negativity for a better understanding of the association between these variables. Based on the findings, it is recommended that the metacognitive beliefs and mental health state of university students be further evaluated. Furthermore, it is proposed that training workshops be implemented based on metacognitive strategy training in order to improve the mental health of these students and form proper identity styles. Finally, it is suggested that metacognitive therapies be provided to eligible students.

\section{Footnotes}

Authors' Contribution: Camelia Sadati and Hooman Namvar developed the study concept and design. Camelia Sadati and Hooman Namvar acquired the data. Camelia Sadati and Bita Nasrolahi analyzed and interpreted the data, and wrote the first draft of the manuscript. All authors contributed to the intellectual content, manuscript editing and read and approved the final manuscript. Hooman Namvar and Bita Nasrolahi provided administrative support.

Conflict of Interests: There is no conflict of interest.

Ethical Approval: The study protocol was approved by the Ethics Committee of the Islamic Azad University, Science and Research Branch in Tehran (code: 123960146971)

Funding/Support: There is no funding or support.

Informed Consent: Written informed consent was obtained from the participants. 


\section{References}

1. Nakhostin-Ansari A, Sherafati A, Aghajani F, Khonji MS, Aghajani R, Shahmansouri N. Depression and Anxiety among Iranian Medical Students during COVID-19 Pandemic. Iran J Psychiatry. 2020;15(3):22835. doi: 10.18502/ijps.v15i3.3815. [PubMed: 33193771]. [PubMed Central: PMC7603582].

2. Mullen S. Major depressive disorder in children and adolescents. Ment Health Clin. 2018;8(6):275-83. doi: 10.9740/mhc.2018.11.275. [PubMed: 30397569]. [PubMed Central: PMC6213890].

3. Gomes AP, Soares ALG, Kieling C, Rohde LA, Goncalves H. Mental disorders and suicide risk in emerging adulthood: the 1993 Pelotas birth cohort. Rev Saude Publica. 2019;53:96. doi: 10.11606/s15188787.20190530012356. [PubMed: 31644774]. [PubMed Central: PMC6802944].

4. Mierau JO, Kann-Weedage D, Hoekstra PJ, Spiegelaar L, Jansen D, Vermeulen KM, et al. Assessing quality of life in psychosocial and mental health disorders in children: a comprehensive overview and appraisal of generic health related quality of life measures. BMC Pediatr. 2020;20(1):329. doi: 10.1186/s12887-020-02220-8. [PubMed: 32620157]. [PubMed Central: PMC7333319].

5. Over $H$. The origins of belonging: social motivation in infants and young children. Philos Trans $R$ Soc Lond B Biol Sci. 2016;371(1686):20150072. doi: 10.1098/rstb.2015.0072. [PubMed: 26644591]. [PubMed Central: PMC4685518].

6. Pesigan IJ, Luyckx K, Alampay LP. Brief report: identity processes in Filipino late adolescents and young adults: parental influences and mental health outcomes. J Adolesc. 2014;37(5):599-604. doi: 10.1016/j.adolescence.2014.04.012. [PubMed: 24931562].

7. Williams AD, Clark TC, Lewycka S. The Associations Between Cultural Identity and Mental Health Outcomes for Indigenous Maori Youth in New Zealand. Front Public Health. 2018;6:319. doi: 10.3389/fpubh.2018.00319. [PubMed: 30483490]. [PubMed Central: PMC6243073].

8. Jung E, Pick O, Schluter-Muller S, Schmeck K, Goth K. Identity development in adolescents with mental problems. Child Adolesc Psychiatry Ment Health. 2013;7(1):26. doi: 10.1186/1753-2000-7-26. [PubMed: 23899433]. [PubMed Central: PMC3751041].

9. Arnett JJ. Emerging Adulthood: What Is It, and What Is It Good For? Child Develop Perspect. 2007;1(2):68-73. doi: 10.1111/j.17508606.2007.00016.x.

10. Arnett JJ. Emerging Adulthood. 2nd ed. New York: Oxford University Press; 2014. doi: 10.1093/acprof:oso/9780199929382.001.0001.

11. Norman E, Furnes B. The Concept of "Metaemotion": What is There to Learn From Research on Metacognition? Emot Rev. 2016;8(2):187-93. doi: 10.1177/1754073914552913. [PubMed: 27110281]. [PubMed Central: PMC4820014].

12. Ahadi B, Mehrinejad A, Moradi F. Cognitive failure in the elderly: the role of mindfulness and meta-emotion. Aging Psychol. 2017;3(2):115-25.

13. Akbari M. Metacognitions or distress intolerance: The mediating role in the relationship between emotional dysregulation and problematic internet use. Addict Behav Rep. 2017;6:128-33. doi: 10.1016/j.abrep.2017.10.004. [PubMed: 29450248]. [PubMed Central: PMC5800590].

14. Guerra-Bustamante J, Leon-Del-Barco B, Yuste-Tosina R, Lopez-Ramos VM, Mendo-Lazaro S. Emotional Intelligence and Psychological WellBeing in Adolescents. Int J Environ Res Public Health. 2019;16(10). doi: 10.3390/ijerph16101720. [PubMed: 31100799]. [PubMed Central: PMC6572191].

15. Sanchez-Alvarez N, Berrios Martos MP, Extremera N. A Meta-Analysis of the Relationship Between Emotional Intelligence and Academic Performance in Secondary Education: A Multi-Stream Comparison. Front Psychol. 2020;11:1517. doi: 10.3389/fpsyg.2020.01517. [PubMed: 32793030]. [PubMed Central: PMC7385306].

16. Suveg C, Jones A, Davis M, Jacob ML, Morelen D, Thomassin K, et al. Emotion-Focused Cognitive-Behavioral Therapy for Youth with Anxiety Disorders: A Randomized Trial. J Abnorm Child Psychol. 2018;46(3):569-80. doi: 10.1007/s10802-017-0319-0. [PubMed: 28580504].

17. Miceli M, Castelfranchi C. Meta-emotions and the complexity of human emotional experience. New Ideas Psychol. 2019;55:42-9. doi: 10.1016/j.newideapsych.2019.05.001.

18. Reifman A, Arnett JJ, Colwell MJ. Emerging Adulthood: Theory, Assessment and Application. J Youth Develop. 2007;2(1):37-48. doi: 10.5195/jyd.2007.359.

19. Fathi MR, Kiamanesh AR, Jomehri F. Emerging Adulthood and Its Characteristics in Iranian University Students. Iran J Educ Soc. 2018;1(7):82-101.

20. Montazeri A, Harirchi AM, Shariati M, Garmaroudi G, Ebadi M, Fateh A. The 12-item General Health Questionnaire (GHQ-12): translation and validation study of the Iranian version. Health Qual Life Outcomes. 2003,1:66. doi: 10.1186/1477-7525-1-66. [PubMed: 14614778]. [PubMed Central: PMC280704].

21. Parsaei I, Sadipour E, Dortaj F, Asadzaeh H. Evaluation of the Structural Model of Achievement Motivation Based on the School Climate and Values Related to Study with the Mediation of Meta-Emotion in Students. QJ Child Ment Health. 2019;5(4):110-21.

22. Yanos PT, Roe D, Lysaker PH. The Impact of Illness Identity on Recovery from Severe Mental Illness. Am J Psychiatr Rehabil.2010;13(2):73-93. doi: 10.1080/15487761003756860. [PubMed: 20802840]. [PubMed Central: PMC2927828].

23. Kukla M, Lysaker PH. Metacognition over time is related to neurocognition, social cognition, and intrapsychic foundations in psychosis. Schizophr Res Cogn. 2020;19:100149. doi: 10.1016/j.scog.2019.100149. [PubMed: 31832339]. [PubMed Central: PMC6889797].

24. Capobianco L, Faija C, Husain Z, Wells A. Metacognitive beliefs and their relationship with anxiety and depression in physical illnesses: A systematic review. PLoS One. 2020;15(9). e0238457. doi: 10.1371/journal.pone.0238457. [PubMed: 32911486]. [PubMed Central: PMC7500039].

25. Pena-Sarrionandia A, Mikolajczak M, Gross JJ. Integrating emotion regulation and emotional intelligence traditions: a meta-analysis. Front Psychol. 2015;6:160. doi: 10.3389/fpsyg.2015.00160. [PubMed: 25759676]. [PubMed Central: PMC4338658].

26. Price CJ, Hooven C. Interoceptive Awareness Skills for Emotion Regulation: Theory and Approach of Mindful Awareness in Body-Oriented Therapy (MABT). Front Psychol. 2018;9:798. doi: 10.3389/fpsyg.2018.00798. [PubMed: 29892247]. [PubMed Central: PMC5985305].

27. Shapiro SL, Carlson LE, Astin JA, Freedman B. Mechanisms of mindfulness. J Clin Psychol. 2006;62(3):373-86. doi: 10.1002/jclp.20237. [PubMed: 16385481].

28. Ghadampour E, Yousefvand L, Radmehr P. The Effect Social Interest Training on Lifestyle in Bullying and Victim Adolescences. Positive Psychol Res. 2017;2(3):67-78. 